\title{
Oral Soft Tissue Chondromyxoma of The Palate Treated by Excision and Platelet Rich Fibrin Grafting: A First Report
}

\author{
Shivika Choudhary, Pavan Manohar Patil*, Vidyadevi Chandavarkar and Aastha Sharma \\ Department of Oral and Maxillofacial Surgery, India
}

*Corresponding author: Pavan Manohar Patil, Professor and Head of Department, Department of Oral and Maxillofacial Surgery,

School of Dental Sciences, India

\begin{tabular}{l} 
ARTICLE INFO \\
\hline Received: 㓞 February 27, 2019 \\
Published: March 14, 2019 \\
\hline Citation: Shivika Choudhary, Pa- \\
van Manohar Patil, Vidyadevi Chan- \\
davarkar and Aastha Sharma. Oral Soft \\
Tissue Chondromyxoma of The Palate \\
Treated by Excision and Platelet Rich \\
Fibrin Grafting: A First Report. Biomed \\
J Sci \& Tech Res 16(1)-2019. BJSTR. \\
MS.ID.002782.
\end{tabular}

ABSTRACT

Chondromas are benign cartilaginous tumours usually localized within the tubular bones of the extremities. Soft tissue chondromas (STCs) are rare and only few cases have been reported in the oral cavity. Based on the degree of differentiation, chondromas may be histologically classified as osteochondroma, chondromyxoma or chondrfibroma. The present case documents the exceptional finding of an 18-year-old with a chondromyxoma of the hard palate mucosa. It was radically excised and the site grafted with autologous platelet rich fibrin (PRF). No recurrence was observed during 3-year follow-up. A concise review of the relevant literature is included.

Keywords: Soft Tissue Chondroma; Palate; Chondromyxoma; Platelet Rich Fibrin

\section{Introduction}

Soft tissues chondromas (STCs) are rare, benign tumours occurring in extraosseous and extrasynovial locations. These tumours are not attached to bone, intra-articular synovium, or periosteum Sera et al. [1]. STCs are usually observed within the soft tissues of the hands and feet, the fingers being frequently affected Papagelopoulos et al. [2]. Other locations reported include the dura, larynx, skin, and fallopian tube Nayler et al. [3]. STCs rarely occur in the oral cavity Sera et al. [1]. Oral sites where these tumours have been reported include the tongue, the cheek, hard and soft palate, the edentulous ridge, master muscle and the masticatory space Vescovi et al. [4]. They are apparently more common in the third and fourth decades of life Papagelopoulos et al. [2]. There are no reliable theories to explain the etiology and pathogenesis of oral STC's. Hypothetically, a origin from aberrant embryonal cartilage or metaplastic change secondary to chronic inflammation or trauma may be considered Sera et al. [1]. A genetic theory based on chromosomes 6, 11 and 12 has also been proposed Cin et al. [4]. Only five cases of STC of the palate have been reported in the literature, one of these being associated with cleft palate Vescovi et al. [4]. However, to the best of our knowledge, this is the first report of a chondromyxomatous variant of chondroma of the palate. The present case reports the exceptional finding of a soft tissue chondromyxoma of the hard palate together with a concise review of the literature. A first of its kind soft tissue regeneration of the hard palate using platelet rich fibrin grafting is also documented.

\section{Case Presentation}

A sixteen-year-old female presented to the Department of Oral and Maxillofacial Surgery, School of Dental Sciences, Sharda University with a complaint of a lump on the inner aspect of her upper jaw sine 3-4 months. She denied history of trauma, surgery or dental treatment in the area. She denied history of drug allergy, weight loss, chronic cough, anorexia, fever, nasal discharge or pain. Her medical history was unremarkable. On examination, a single, lobulated, non ulcerated growth was observed on the palatal mucosa abutting the three right maxillary molars (Figure 1). The growth measured $2.5 \mathrm{~cm} \times 1.5 \mathrm{~cm}$ in dimension and was pedunculated with a wide base. The growth was immobile, non tender and firm on palpation. Draining lymph nodes were not 
enlarged. Radiographic examination revealed no bony involvement. A provisional diagnosis of pleomorphic adenoma was made. After obtaining a written informed consent, an excision of the growth was performed under local anesthesia. A $5 \mathrm{~mm}$ margin of normal palatal mucosa was included in the surgical specimen (Figure 2). Histopathologic findings revealed areas of chondroid and myxoid tissue in lobular pattern (Figure 3). Numerous chondrocytes within the lacuna were observed (Figure 4). Chondrocytes were plump to spindle shape with no nucleus. Myxomatous areas showed stellate shaped cells.

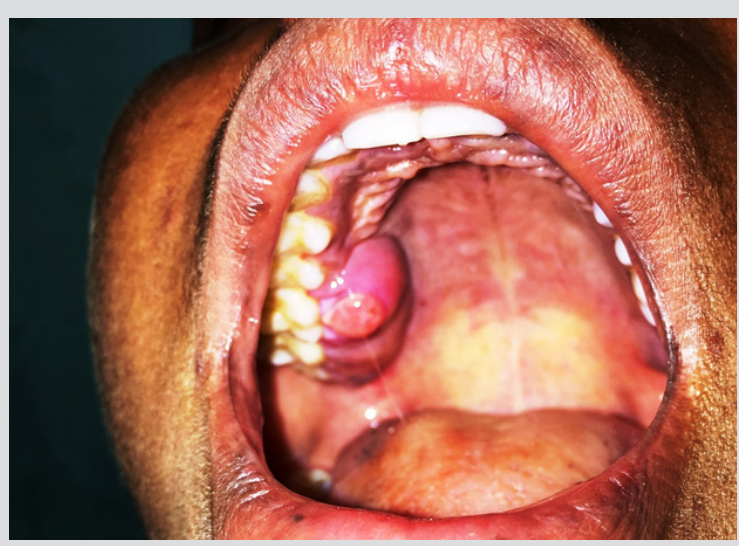

Figure 1: Growth on the Hard Palate.

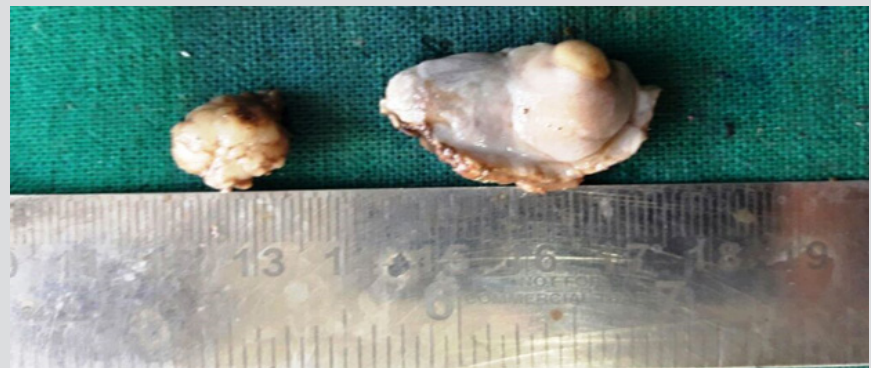

Figure 2: Excised Surgical Specimen.

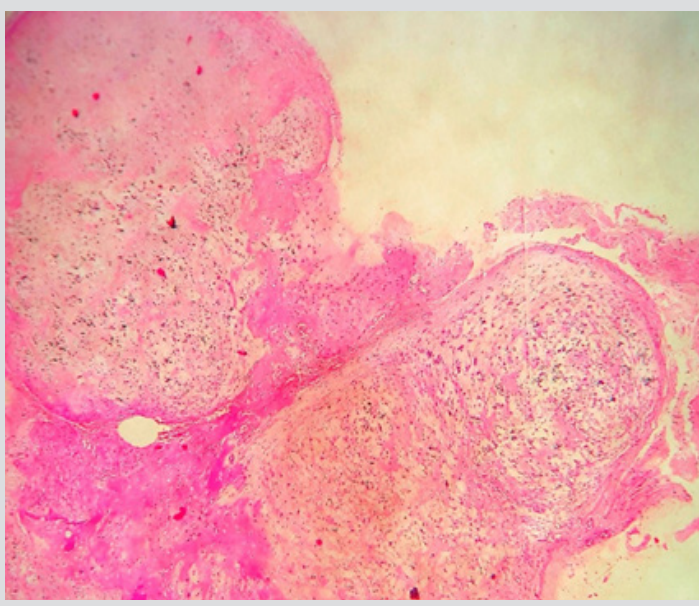

Figure 3: H and E Stain (100x) Showing Chondroid And Myxoid Area.

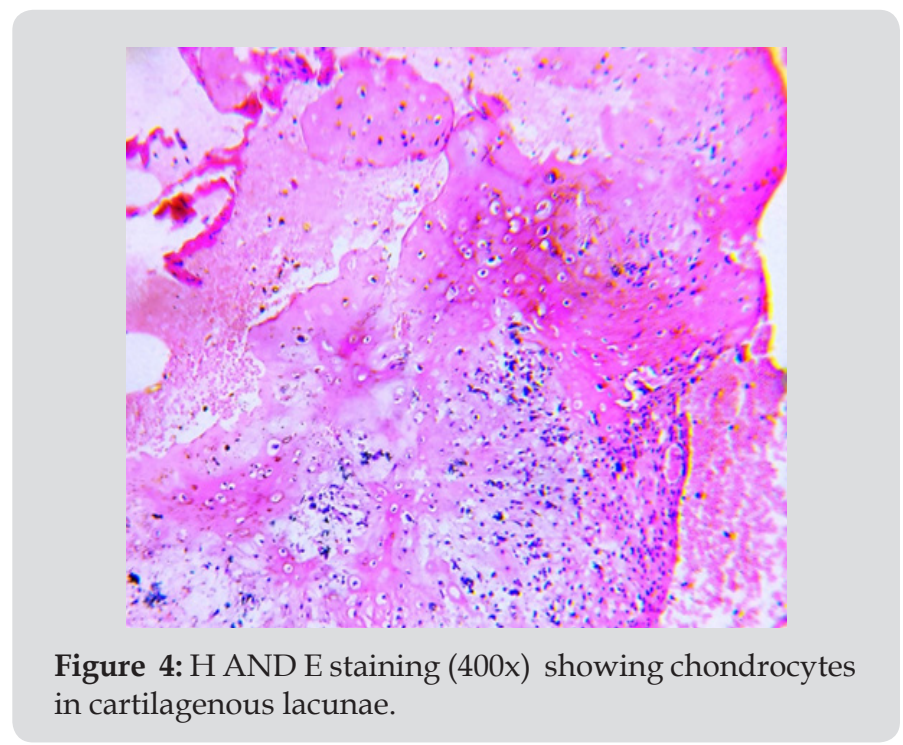

Few endothelial lined blood vessels and mild chronic inflammatory infiltrate was also seen. However fibrotic component was scanty. In few areas scanty fibrous septa divided chondromyxoid stroma into lobes. Immuno histochemistry revealed that the lesional cells positively reacted to vimentin and S-100 stains. Based on these findings, a diagnosis of chondromyxoma was established. 10 $\mathrm{ml}$ of blood was withdrawn from the cephalic vein in the anticubital fossa of the right arm. The collected blood was centrifuged in a sterile test tube at $3000 \mathrm{rpm}$ (Royal Rectangular 4 Tube Centrifuge Machine, RSW-140A, Royal Scientific Works, Ambala, Haryana, India) to obtain platelet rich fibrin Choukroun et al. [7] (Figure 4). The PRF gel was compressed to form a sheet and was sutured to the margins of the defect (Figure 5). Patient returned for follow up at 2 , 4 and 6 weeks postoperatively. At the 2 week interval, another sheet of PRF was sutured to the defect to add as an additional surface lining (Figure 6). The area healed uneventfully in six weeks (Figure 7). There has been no recurrence of the lesion on a 3 year follow up.

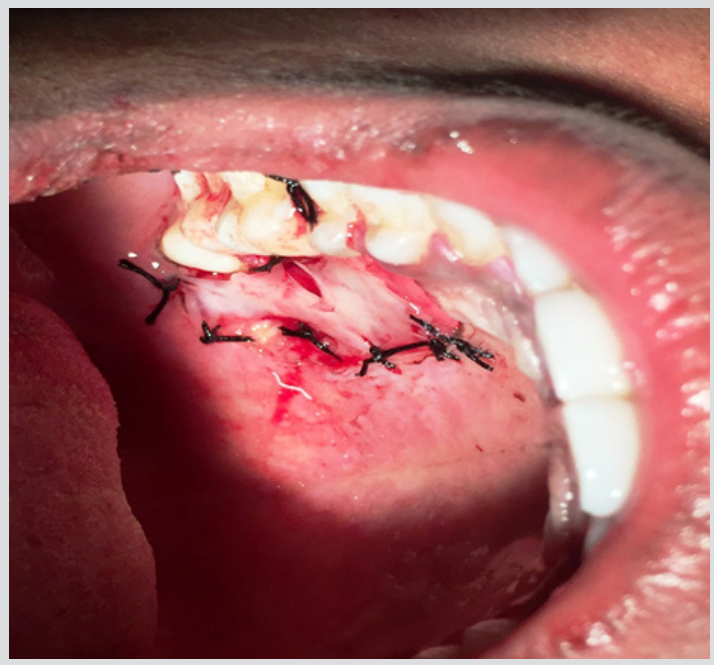

Figure 5: Postexcision Defect Lined ith Platelet Rich Fibrin Membrane. 


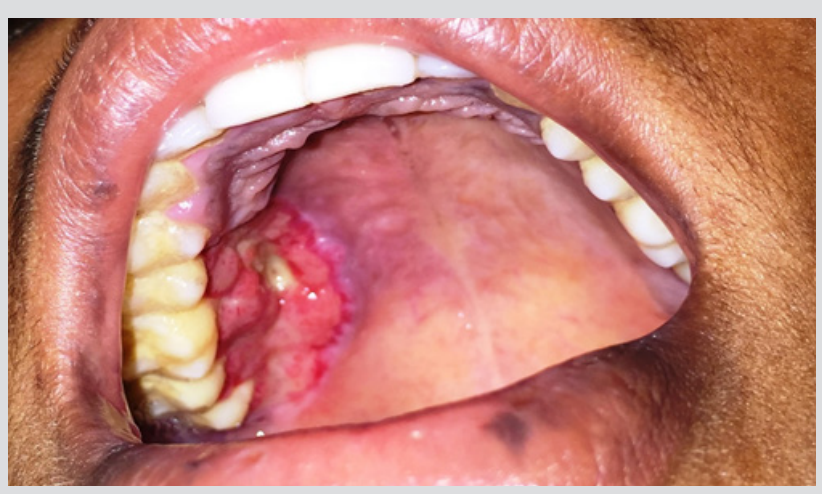

Figure 6: Healing AT 2 weeks.

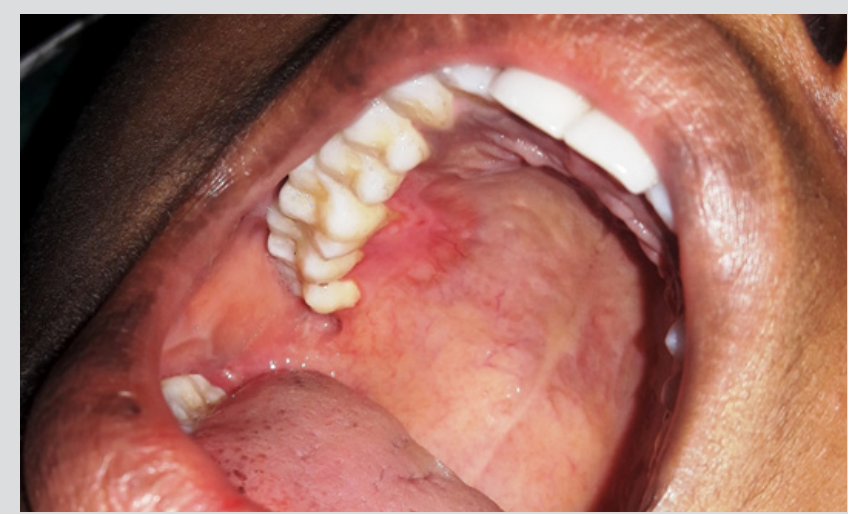

Figure 7: Healed Surgical Site at Six Weeks.

\section{Discussion}

Swellings on the hard palate are very common and differential diagnosis may include minor salivary glands neoplasms, traumatic or idiopathic fibrous reactions, acute or chronic infectious processes. Our case is a rare manifestation of the chondromyxoid variant of oral soft tissue chondroma. Age of the patient (16 years) is within the known age group of usual occurrence which is the second or third decades of life. This is only the sixth reported case of palate chondroma and the first with myxoid variation Vescovi et al. $[4,5]$. Wide excision is the recommended treatment modality for the condition Vescovi et al. [4]. The majority of patients with a diagnosis of STCs are middle-aged with a range between 26 and 60 years Nayler et al. [3]. Our patient was sixteen years of age in contrast to the average age reported for STCs. It has been reported that the common site for oral STC is the lateral borders and the dorsum of the tongue Onodera et al. [7]. However, STCs have been additionally reported in the soft palate, hard palate, cheek, skull base and maxilla, lower lip, masseter muscle, tonsil, flabby ridge beneath dentures and the masticatory space Vescovi et al. [4]. Chondromas, or variations of chondromas (chondromyxoma, osteochondroma, fibrochondroma), may form from retained embryonic cartilage, or may develop from proliferative young connective tissue cells or ancestors of cells which, when duly differentiated, are known as osteoblasts Sleeper [6].
The stage of differentiation will determine the type of tumour, which may be a pure fibroma, chondroma, or osteoma. The pure chondroma may undergo myxomatous degeneration producing a chondromyxoma which in itself is benign but has malignant potentialities Sleeper [6]. Normally, the chondromyxoma is a well-encapsulated tumor, and growth occurs at the periphery by apposition of cells from the capsule Sleeper [6]. As the tumour cells grow from the periphery of the mass, their potential to break through the capsule and lead to malignant change must be borne in mind Sleeper [6] and therefore they must be excised with generous margins. A 10-15\% recurrence rate has been reported after surgical excision of oral STCs Nayler et al. [3]. However, there has been no recurrence in our patient at one year follow up.

Platelet-rich fibrin (PRF) belongs to a new generation of platelet concentrates, with simplified processing and without biochemical blood handling Choukroun et al. [1]. PRF can be considered as a natural fibrin-based biomaterial favourable to the development of a microvasculature and able to guide epithelial cell migration to its surface Choukroun et al. [9]. This matrix also contains leukocytes and promotes their migration. These attributes help protect open wounds and accelerate healing. Similar effects were observed in our patient. In case of larger defects or in cases like ours as well, surgeons have the option of stabilizing the PRF membrane with a titanium pin at the centre of the bony palate to addition anchor the graft to the bony surface. We repeated the PRF membrane placement at 2 weeks to additionally stimulate the healing process and protect the granulating wound. The possibility of repeating the PRF membrane placement as many times as necessary makes this an attractive option in lining oral soft/hard tissue defects of small to moderate size Pathak et al. [10]. Additional advantages of PRF as a reconstructive option in our patient was no donor site morbidity, simplicity of the procedure and negligible additional cost.

\section{References}

1. H Sera, T Shimoda, S Ozeki, T Honda (2005) A case of chondroma of the tongue. International Journal of Oral and Maxillofacial Surgery 34(1): 99-100.

2. Papagelopoulos PJ, Savvidou OD, Mavrogenis AF, Chloros GD, Papaparaskeva KT, Soucacos PN (2007) Extraskeletal chondroma of the foot. Joint Bone Spine 74(3): 285-288.

3. S Nayler, S Heim (2002) Soft tissue chondroma. Tumors of soft tissue and bone. In: WHO Classification of Tumors (Chondro-Osseous Tumours), DM Fletcher, KK Unni, F Mertens (Eds.), WHO, Lyon, France, pp. 180-181.

4. Paolo Vescovi, Marco Meleti, Elisabetta Merigo, Maddalena Manfredi, Domenico Corradi, et al. (2014) Soft Tissue Chondroma of the Oral Cavity: An Extremely Rare Tumour Localized on the Hard Palate. Case Reports in Medicine 414861: 5.

5. PD Cin, $H$ Qi, R Sciot, $H$ van den Berghe (1997) Involvement of chromosomes 6 and 11 in a soft tissue chondroma. Cancer Genetics and Cytogenetics 93(2): 177-178.

6. Sleeper EL (1952) Chondromyxoma of the mandible. Oral Surg Oral Med Oral Pathol Oral Radiol Endod 5(8): 816-822.

7. K Onodera, H Xu, S Kimizuka, S Echigo, K Ooya (2005) Chondroma of the cheek: a case report. International Journal of Oral and Maxillofacial Surgery 34(8): 924-926. 
8. Choukroun J, Adda F, Schoeffler C, Vervelle A (2001) Une opportunite en paro-implantologie: le PRF. Implantodontie 42: 55-62.

9. Choukroun J, Diss A, Simonpieri A, Girard MO, Schoeffler C, et al. (2006) Platelet-rich fibrin (PRF): a second-generation platelet concentrate. Part $\mathrm{V}$ : histologic evaluations of PRF effects on bone allograft maturation in

\section{ISSN: 2574-1241}

DOI: 10.26717/BJSTR.2019.16.002782

Pavan Manohar Patil. Biomed J Sci \& Tech Res

(C) (P) This work is licensed under Creative

Submission Link: https://biomedres.us/submit-manuscript.php sinus lift. Oral Surg Oral Med Oral Pathol Oral Radiol Endod 101(3): 299303 .

10. Pathak H, Mohanty S, Urs AB, Dabas J (2015) Treatment of Oral Mucosal Lesions by Scalpel Excision and Platelet-Rich Fibrin Membrane Grafting: A Review of 26 Sites. J Oral Maxillofac Surg 73(9): 1865-1874.

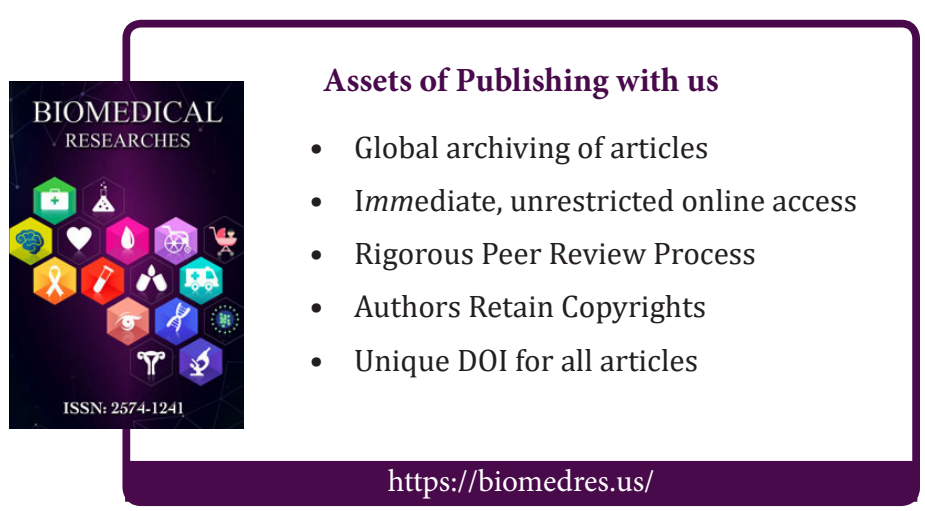

